This is a postprint version of the following published document:

Cancelo, José Ramón; Espasa, Antoni. Using high-frequency data and time series models to Improve yield management. International Journal of Services Technology and Management. 2001, vol. 2, no 1-2, p. 59-70. Available in: http://dx.doi.org/10.1504/IJSTM.2001.001591

(C) Inderscience 


\title{
Using high-frequency data and time series models to improve yield management
}

\section{José Ramón Cancelo}

Dpto. Economía Aplicada II, Facultad de Ciencias Económicas y Empresariales, Universidad de La Coruña, Campus de La Zapateira, 15071, La Coruña, Spain.

\section{Antoni Espasa}

\author{
Dpto. Estadística y Econometría, Facultad de Ciencias Jurídicas y \\ Sociales, Universidad Carlos III de Madrid, c/ Madrid 126, 28903 \\ Madrid, Spain.
}

\begin{abstract}
High-frequency (less than monthly) time series data provide valuable information for designing the adequate yield policy of the organization. However, it is not easy to extract this information from raw data; although the evolution of the series is usually induced by stable patterns of behaviour of the economic agents, these patterns are so complex that simple smoothing techniques or subjective forecasting cannot consider all underlying factors. In this paper we discuss time series models as a tool for carrying out a full and efficient analysis. The main ideas are illustrated with an application to Spanish daily electricity consumption.
\end{abstract}

Keywords: Organizational learning; forecasting; simulation; signal extraction; electricity consumption.

Biographical notes: José Ramón Cancelo is professor of Business and Economic Statistics at the Universidad de La Coruña, Spain. He received his $\mathrm{PhD}$ in 1986 from the Universidad Autónoma de Madrid. His primary interests are in applied time series analysis and dynamic models.

Antoni Espasa is professor of Econometrics at the Universidad Carlos III de Madrid. He obtained his PhD from the London School of Economics in 1975. He has been Chief Economist at the Research Unit of the Banco de España. His published research includes studies in spectral econometrics, dynamic models, applied econometrics, forecasting, signal extraction in time series and modelling daily series of economic activity.

\section{Introduction}

The implementation of time series models (henceforth TSM) for efficient analysis of high frequency data on activity variables is one of the most promising fields in applied 
economics. There exists a wide range of variables (consumption of electricity, water, gas or petrol, withdrawals of funds from financial institutions, commuters using public transport, traffic levels, production levels, sales, lumber and pulp industries, etc.) which are observed weekly, daily or even hourly. Time series of thousands of observations, with valuable information on the characteristics of economic phenomena, are available to the analyst. The problem lies in how to handle this vast amount of information for efficient decision-making.

Forecasting systems have developed in response to new capabilities in data accumulation, among other factors [1]. The purpose of this paper is to highlight the usefulness of TSM in analysing high frequency data; we focus on short-term forecasting because this is the main concern when dealing with high frequency information, although some other applications are also reviewed. Throughout the paper the expression "high frequency data' will refer to data observed at least twice per month, the sampling interval being one week, one day, one hour or any other time span that meets this condition. 'Short-term forecasting' refers to the specific problem of forecasting this type of data.

The application to yield management and specifically to the optimal sale of perishable products is straightforward: a good model will provide an adequate representation of the data generating process, which can be used to reduce the uncertainty of demand forecasts; supply can be adjusted accordingly, and costs be reduced.

The paper is organized as follows: general pros and cons of TSM are discussed in section two, and these are compared with some competing approaches; an application to daily electricity consumption is discussed in section three; and the main conclusions are summarized in section four.

\section{Forecasting techniques for high frequency data}

For the purposes of this paper, forecasting techniques can be broadly separated into subjective forecasts and model-based methods. Although the former are usually referred to as judgmental forecasting, we think that judgment plays a central role in the forecasting and planning process, whatever the specific forecasting technique involved. As Hogarth and Makridakis [2] point out, decisions on the specification of goals, choices concerning data sources, forecasting methodologies, adjustments to basic forecasts and the assessment of implementation strategies all make the task of forecasting, in the broadest sense, a matter of judgment.

\subsection{Subjective forecasts}

In most organizations, short-term forecasting is charged to qualified experts who produce reliable forecasts due to their experience [3]. Moreover, sometimes non-systematic, heterogeneous information is available: it is difficult to introduce this type of information into a quantitative model, but it may be processed and incorporated by an expert into the final forecasts [4].

However, purely subjective forecasting is not the best choice for setting up a forecasting system for high frequency data, because 
- It is very difficult to transmit to other people the way information is processed to produce forecasts. As a consequence, the whole planning process is highly dependent on the permanence of particular persons in the organization.

- It is an expensive forecast, as it takes up a significant number of the working hours of qualified personnel. Detailed analysis by an expert is justified at specific times where complex conditions prevail, but not in normal circumstances.

- Socioeconomic conditions change, and so the variables we are interested in react to changes in the explanatory variables in a more sophisticated way, thus subjective learning becomes more difficult and new kinds of tools must be considered.

- Recent research has focused on the inconsistencies of human judgment, even that of highly qualified experts: see Goodwin and Wright [5,3] and references therein; see also Ashouri [6].

\subsection{Quantitative methods}

Weekly, daily or hourly activity series display the same characteristics as monthly or quarterly series, even though their short term components (seasonal, irregular, calendar effects, outliers, etc) are much more complex. Most components are induced by stable patterns of behaviour by the economic agents, so that a model - i.e., an explicit representation of the data generation process (DGP) - may be built up and used to obtain informative forecasts. However, because of this complexity, simple smoothing techniques do not provide an adequate approximation to the DGP: true TSM are needed if data are to be processed in an efficient way to produce optimal forecasts.

The main purposes of a TSM are

- To generate reliable forecasts with no need for supplementary evaluation by an expert.

- To become an operative tool within the organization: management support, user involvement, personal stake and the implementation strategy are as relevant as accuracy is to forecasting success [7].

- To produce an adequate anchor in the presence of very complex conditions. Goodwin and Wright [3] point out that it seems that a process of anchoring and adjustment is used in judgmental extrapolation and although the joint occurrence of anomalous events may require the forecast of the model to be adjusted by an expert, this forecast is still the best starting point for the subjective adjustment.

- To help organizations become better learning systems: organizational learning is defined as the capacity within an organization to maintain or improve performance based on experience [8]. A TSM is not just a tool for acquisition of knowledge, it concerns its transfer: knowledge becomes institutionally available, as opposed to being the property of selected individuals.

- To quantify the influence of explanatory variables with a double purpose

- better forecasts may be produced if accurate predictions for explanatory variables are available; and

- simulation exercises may be carried out. 
- To extract a more reliable signal by eliminating from the observed series the effect of added noise, in order to use it in the decision making process.

The most serious objection to TSM is the amount of resources needed to build and maintain them. Makridakis et al. [9] consider four elements of cost in a forecasting method: development costs, data storage costs, maintenance costs and the costs of repeated applications. In respect of the total amount, development costs are by far the most important, in relative terms. Maintenance costs are important also, as they include adjusting the model whenever changes in the basic pattern are detected. In contrast, once a TSM is implemented, storage and repeated applications costs are almost negligible.

Building a model for a typical high frequency series is always a difficult task, and a detailed analysis has to be carried out to decide which variables will have their own TSM. Although each case deserves specific consideration, a good ground rule is to determine the monetary loss as a function of the prediction error for all variables. The loss functions are next compared with the actual total cost of a TSM, so that a model is built only when a substantial saving is expected (but this is not as simple as it seems: see for instance Remus [10] on the consequences of the criterion being a nonlinear function of the variable).

\section{A case study: daily consumption of electricity in Spain}

\subsection{The problem}

Electricity consumption is a typical example of the problem we are considering in this paper: long-time series of hourly and daily data are available. It is a perishable good, because overproduction (the difference between total production and instantaneous consumption) is wasted, so a very accurate forecast of the demand is needed. Short-term electricity consumption forecasting deserves a noteworthy place in the literature of high frequency data analysis: see, inter alia, Bogard et al. [11], Bunn and Farmer [12], Gross and Galiana [13], Adams et al. [14] or Engle et al. [15]: References to closely related problems also provide valuable guidance: see for instance Ashouri [6] on gas demand.

When we were charged with building a forecasting system for Spanish daily consumption of electricity, which could also help in setting weekly and hourly production schedules, we approached the task in the following way:

1 To begin with, homogeneous series of daily data covering several years was collected. We had to define consumption in an operative way, in order to separate actual demand from final destination of overproduction. Homogeneous time series for the explanatory variables were also prepared.

2 The second step consisted of determining the main characteristics of the resulting series.

3 Next we built a complex nonlinear transfer function model to explain these characteristics.

4 From this model, daily forecasts have been obtained automatically. Weekly forecasts were derived from aggregating daily ones; hourly forecasts could be produced by identifying typical load curves and distributing daily forecasts accordingly. 
5 The model has also been used to improve our knowledge of the influence of explanatory variables, and to extract a more reliable signal of electricity consumption.

These five stages are related to what Murdick and Georgoff [1] call the central components of a forecasting system: the input data (point 1), the output we desire (points 4 and 5), the assumptions about the behaviour of the variables (point 2 and the extra sample information used in point 3 ) and the process of relating dependent to independent variables (the model that results from point 3 ).

In the following sections a more detailed description is given. However, in doing so our purpose is simply to use this application as an example of the potential use of TSM. As a consequence some relevant results concerning the specific problem of modelling electricity consumption will be omitted. A complete exposition can be found in Cancelo and Espasa [16].

\subsection{The data}

The variable to model is the net demand for electrical energy, defined as total production from all sources plus international interchanges balance, less intermediate autoconsumption and pumping consumption. The only available data referred to mainland Spain taken as a whole, almost half a million square kilometers with more than 36 million inhabitants.

The original model was built for the sample 1983-1989. The series displays a growing trend; annual and weekly seasonal oscillations; complex calendar effects related to changes in the usual pattern of working conditions (holidays, vacation periods, Easter); some anomalous values caused by strikes, elections, and the like. Moreover, weather conditions are known to have a significant influence.

\subsection{Overview of the model}

From section 3.2 it follows that observed consumption in day $t\left(C_{t}\right)$ can be expressed as:

$$
\mathrm{C}_{\mathrm{t}}=\mathrm{TC}_{\mathrm{t}} * \mathrm{SCt} * \mathrm{CE}_{\mathrm{t}} * \mathrm{IA}_{\mathrm{t}} * \mathrm{CMV}_{\mathrm{t}} * \mathrm{IC}_{\mathrm{t}}
$$

where

- $\quad \mathrm{TC}_{\mathrm{t}}$ trend consumption, related to socioeconomic factors;

- $\quad \mathrm{SC}_{\mathrm{t}}$ seasonal consumption;

- $\mathrm{CE}_{\mathrm{t}}$ calendar effect;

- $\mathrm{IA}_{\mathrm{t}}$ intervention analysis to deal with anomalous observations which deserve specific consideration;

- $\mathrm{CMV}_{\mathrm{t}}$ contribution of meteorological variables;

- $\mathrm{IC}_{\mathrm{t}}$ irregular consumption, which embraces all transitory disturbances not included in previous components. 
The model is completely multiplicative, so that all components are assumed to increase in direct proportion to the trend level: it seems to be the general rule in activity series, no matter what the frequency of observation of the data [11]. Taking logarithms

$$
\ln C_{t}=\ln \mathrm{TC}_{\mathrm{t}}+\operatorname{lnSC} \mathrm{C}_{\mathrm{t}}+\ln \mathrm{CE}_{\mathrm{t}}+\ln \mathrm{IA}_{\mathrm{t}}+\ln \mathrm{lMV}_{\mathrm{t}}+\ln \mathrm{IC}_{\mathrm{t}}
$$

From (1) a basic consumption $\left(\mathrm{BC}_{\mathrm{l}}\right)$ can be defined

$$
\ln B C_{t}=\ln C_{t}-\ln C E_{t}-\ln I A_{t}-\ln C M V_{t}=\ln T_{t}+\ln S C_{t}+\ln I C_{t}
$$

Basic consumption displays a smooth evolution and may be explained in a satisfactory way from its past values

$$
\ln B C_{t}=b_{1} \ln B C_{t-1}+\ldots+b_{p} \ln B C_{t-p}+\text { residual }_{t}
$$

Calendar effects and intervention analysis can be expressed as

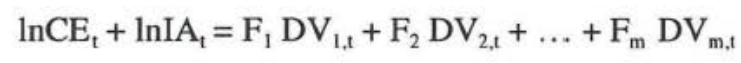

where $\mathrm{DV}_{\mathrm{i}, \mathrm{t}}$ denotes a dummy variable that indicates whether a specific calendar effect or an anomaly happens in $\mathrm{t} ; \mathrm{F}_{\mathrm{i}}$ denotes its dynamic filter, which simplifies into a single coefficient if $\mathrm{DV}_{i, t}$ has no dynamic effect.

As for the contribution of meteorological variables,

$$
\operatorname{lnCMV} V_{t}=G_{1} M_{1, t}+G_{2} M V_{2, t}+\ldots+G_{n} M V_{n, t}
$$

where $\mathrm{MV}_{\mathrm{i}, \mathrm{t}}$ stands for a meteorological variable and $\mathrm{G}_{\mathrm{i}}$ for its dynamic filter, which need not be a linear one.

By combining (2), (3), (4) and (5) it follows that $\operatorname{lnC} C_{t}=b_{1} \operatorname{lnBC} C_{t-1}+\ldots+b_{p} \operatorname{lnBC} C_{t-p}+F_{1} D_{1, t}+F_{2} D_{2, t}+\ldots+F_{m} D_{m, t}+G_{1} M_{1, t}+G_{2}$ $\mathrm{MV}_{2, \mathrm{t}}+\ldots+\mathrm{G}_{\mathrm{n}} \mathrm{MV}_{\mathrm{n}, \mathrm{t}}+$ residual $_{\mathrm{t}}$

In order to express the model solely in terms of observable variables, from (2), (4) and (5)

$$
\begin{aligned}
& \operatorname{lnBC} C_{t-i}=\ln C_{t-i}-\operatorname{lnCE} E_{t-i}-\operatorname{lnIA} A_{t-i}-\operatorname{lnCMV} V_{t-i}=\operatorname{lnC} C_{t-i}-F_{1} D V_{1, t-i}-F_{2} D V_{2, t-i}-\ldots .-F_{m} \\
& \mathrm{DV}_{\mathrm{m}, \mathrm{t}-\mathrm{i}}-\mathrm{G}_{1} \mathrm{MV}_{1, t-\mathrm{i}}-\mathrm{G}_{2} \mathrm{MV}_{2, \mathrm{t}-\mathrm{i}}-\ldots-\mathrm{G}_{\mathrm{n}} \mathrm{MV}_{\mathrm{n}, \mathrm{t}-\mathrm{i}}
\end{aligned}
$$

and by substituting in (6) the final form of the model results in

$\ln \mathrm{C}_{\mathrm{t}}=\mathrm{b}_{1} \ln \mathrm{C}_{\mathrm{t}-1}+\ldots+\mathrm{b}_{\mathrm{p}} \ln \mathrm{C}_{\mathrm{t}-\mathrm{p}}+\mathrm{F}_{1} * \mathrm{DV}_{\mathrm{l}, \mathrm{t}}+\mathrm{F}_{2} * \mathrm{DV}_{2, \mathrm{t}}+\ldots+$

$+\mathrm{F}_{\mathrm{m}} * \mathrm{DV}_{\mathrm{m}, \mathrm{t}}+\mathrm{G}_{1} * \mathrm{MV}_{1, \mathrm{t}}+\mathrm{G}_{2} * \mathrm{MV}_{2, \mathrm{t}}+\ldots+\mathrm{G}_{\mathrm{n}} * \mathrm{MV}_{\mathrm{n}, \mathrm{t}}+$ residual $_{\mathrm{t}}$

In (8) all observations are handled in a single, general model, which covers all potential variations in electricity consumption due to changes in the explanatory variables. Database management is heavily simplified and forecasts are easily obtained automatically and these are two major conditions for the system to be really useful. 


\subsection{On modelling the components}

\subsubsection{Basic consumption}

Attempting to model trend and seasonality by including explanatory variables is unfeasible in most cases, because sound data observed with the required sampling interval is seldom available. However, their contribution to the present observed value can be approximated quite well by using previous values of electricity consumption, due to the fact that the underlying factors change slowly. Relating trend and seasonality to the past history of the variable allows the resulting estimates to adapt to recent observations $[17,18]$, and this flexibility is one of the main determinants of the success of modern time series analysis.

\subsubsection{Calendar effects}

Although the literature has focused mainly on calendar effects in monthly series, they also exist in higher frequency series [19]. In fact, the smaller the sampling interval the more important the influence of the calendar.

Take for instance a holiday. In most cases it will have a minor influence on monthly data; but in a daily series its presence distorts the whole normal weekly pattern. As a consequence, if its effect is not specifically considered then poor forecasts for the day of the holiday and for the following days will result. The trouble is more serious in Latin countries like Spain than in the US where a given holiday usually falls on the same day of the week. In Latin countries however, the general rule is to fix the date of the month, so that it may fall on any day of the week; and this mobility increases the distorting effect.

A TSM makes it possible to analyse in full detail the influence of the calendar: a large sample is carefully screened, stable patterns of behaviour for each type of effect are detected and general rules for forecasting are stated.

As an example, Table 1 summarizes the estimated effects of holidays on Spanish electricity consumption: an estimated coefficent of 30 , for instance, means that observed consumption would be $30 \%$ higher if the holiday did not exist. From Table 1 it can be seen that in our series

- the distortion varies according to the day of the week on which the holiday falls; and

- there is a dynamic effect, so that a holiday falling on t alters the consumption of two or more days.

Table 1 Estimated effects of holidays on Spanish daily electricity consumption

\begin{tabular}{lcccccc}
\hline $\begin{array}{l}\text { Day of the } \\
\text { holiday }\end{array}$ & \multicolumn{5}{c}{ Effect on } \\
\hline & MON & TUE & WED & THU & FRI & SAT \\
MON & 30.9 & 4.1 & & & & \\
TUE & 10.7 & 35.1 & 3.2 & & & \\
WED & & & 30.4 & 3.8 & & \\
THU & & & 29.3 & 11.6 & 2.6 \\
FRI & & & & 28.8 & 9.1 \\
SAT & & & & & 8.2 \\
\hline
\end{tabular}




\subsubsection{Meteorological variables}

Among meteorological variables, temperature is the most important. Our measure of temperature is a weighted mean of maximum daily temperatures registered in ten selected observatories throughout the whole country. To model the relationship between this indicator and electricity consumption, the following extra sample information must be taken into account

- The relationship is U-shaped: there are two limits of temperature, $\mathrm{T}^{*}$ and $\mathrm{T}^{* *}$, which define a neutral zone so that temperatures within this interval do not influence consumption. Below $\mathrm{T}^{*}$ we enter into the cold zone, and above $\mathrm{T}^{* *}$ into the hot zone. In both zones the response function is also expected to be nonlinear. We have estimated that in our series $\mathrm{T}^{*}=20 \mathrm{C}(68 \mathrm{~F})$ and $\mathrm{T}^{* *}=24 \mathrm{C}(75.2 \mathrm{~F})$.

- In daily data a dynamic response is expected, as consumption in day t depends on observed temperatures in $\mathrm{t}, \mathrm{t}-1, \ldots, \mathrm{t}-\mathrm{h}$.

- Exhaustion effects may exist when the temperature is so low (high) that all heating (cooling) systems are operating at full capacity, thus additional decreases (increases) of temperature will have no effect on observed consumption.

- The influence of a given temperature may be different for a working day than for a non-working day, or vary according to the season, etc.

- If the sample is several years in duration, the stock of appliances may increase, and shifts in the response function along the sample should be sought.

All these effects have been tested and modelled in our application, so that we obtained an in-depth knowledge of the relationship between consumption and temperature in our problem.

The effects of other meteorological phenomena of lesser importance (which Ashouri [6] calls misery factors) are harder to model: homogeneous series for the whole sample are not available, and the forecasts provided by the weather centre are not reliable enough. As a consequence the model does not take them into account, although experts may adjust the forecasts of the model for their influence in the presence of very extreme conditions.

\subsection{On using the model}

\subsubsection{Forecasting}

The final model has a residual standard error equal to 0.0130 , which entails a $90 \%$ confidence interval for the one period forecast equal to plus/minus $2.13 \%$ times the point forecast. It represents a major improvement in respect of previous holistic forecasts. In fact, the actual improvement was greater: the model explains sudden variations in consumption caused by unexpected changes in weather conditions, and major errors are much less common; for this series the extra cost occasioned by a poor forecast is a convex function of the prediction error, so that a remarkable saving is achieved by eliminating major errors.

The model can also be used to obtain provisional forecasts of consumption with a higher level of time aggregation, and these forecasts may appear as inputs to models 
explaining other variables. Bodo et al. [20] use daily data on electricity consumption to forecast monthly consumption, and the latter to forecast the monthly industrial production index. While the official figure for the production index for month $\mathrm{M}$ is available by the end of $\mathrm{M}+2$, with their proposal a reasonably reliable forecast can be advanced once the first fortnight electricity consumption of $\mathrm{M}$ is known.

\subsubsection{Simulation}

Given that calendar effects and weather variables are explicitly introduced in the model, the behaviour of electricity consumption under different scenarios may be simulated. As an example, assume maximum daily temperature has been constant at $16 \mathrm{C}(60.8 \mathrm{~F})$ during the whole month of January. On Monday, 1 February, it suddenly falls to $11 \mathrm{C}(51.8 \mathrm{~F})$, remaining there for a week; then on Monday, 8 February, it returns to $16 \mathrm{C}$ and remains unchanged thereafter. Assume also that on Wednesday, 3 February, a successful 24-hour general strike takes place.

For the purposes of our analysis we may consider that on January 31 we were in equilibrium; the sudden fall of temperature and the general strike are exogenous transitory disturbances, and in the long run consumption will return to equilibrium. However, it is interesting to observe how consumption reacts in the short term: Figure 1 displays the estimated effects from Saturday, 30 January, to Tuesday, 16 February.

Figure 1 Simulating the influence of calendar effects and temperature on the consumption of electricity: an example

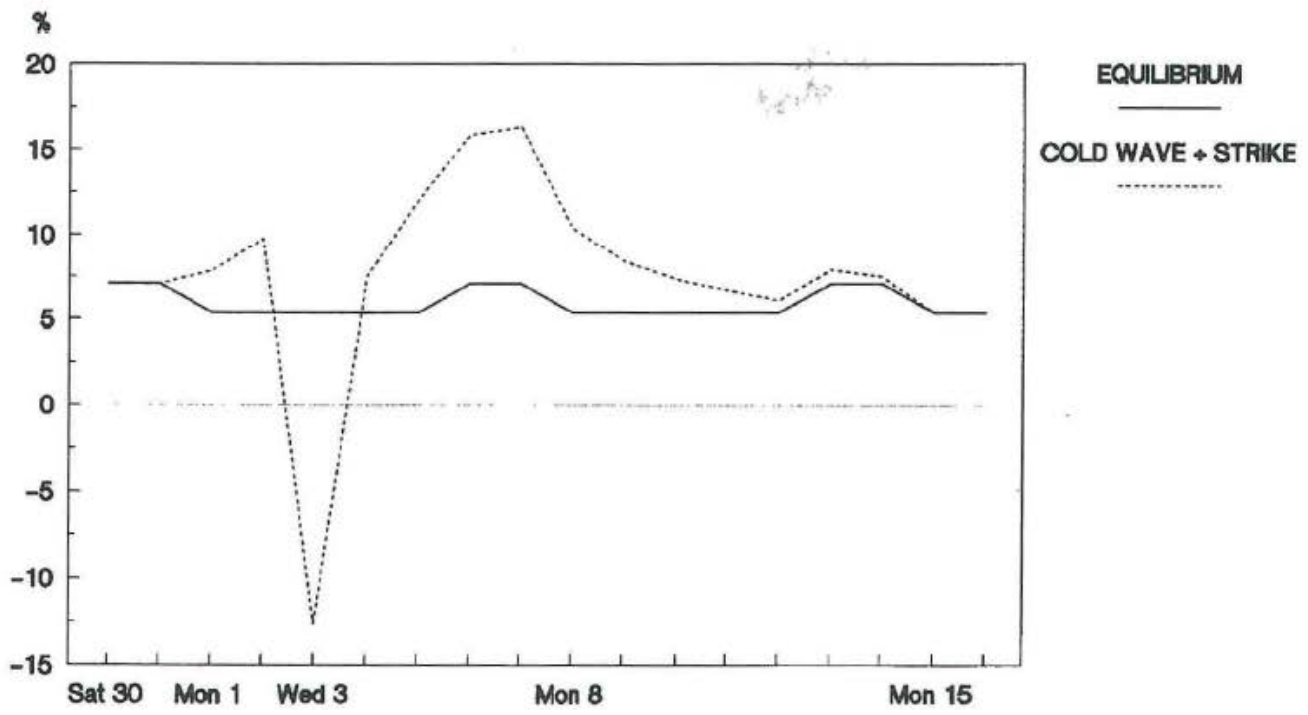

Equilibrium is characterized by a temperature at the cold zone, so there is overconsumption in the situation where temperature has no influence. The solid line shows over-consumption in equilibrium, expressed as the relative increase in respect of normal consumption with no temperature effects. Notice the peaks at weekends, due to the fact that in our series the effect of a given temperature is higher on non-working days. 
The broken line refers to the proposed scenario: over-consumption (removing the influence of the strike) is higher than at equilibrium, because temperature is lower. The dynamic effect of temperature is easy to see: the distortion caused by the cold wave lasts until February 14, although temperature has returned to equilibrium on 8 February. The contribution of the strike is also very clear and in order to estimate its effect we treated it as if it were a holiday falling on a Wednesday.

The gap between both lines measures the influence of transitory disturbances, and the total effect of the cold wave plus the strike results from aggregating daily gaps.

\subsubsection{Signal extraction}

The previous example has shown that our variable is heavily influenced by disturbances which distort time comparisons, to the point of making them uninformative. With a TSM these types of effects can be eliminated, so that a more informative signal results; see Cancelo and Espasa [21], whose main results are summarized in Figure 2.

The broken line displays the relative change in the observed series relating to the same month of the previous year. The solid line is computed from a daily series of corrected consumption. We first eliminate from the observed series the effect of every type of disturbance that may distort time comparisons (see the original paper for details); then daily data are aggregated to form a monthly series, and relative growth is computed.

Figure 2 shows that the corrected series of growth displays a smoother evolution, so that most of the peaks and troughs of the observed series of growth are caused by short term disturbances. As a consequence, it seems inaccurate to base decision-making on original growths.

Figure 2 Observed and corrected growths of the monthly consumption of electricity in Spain

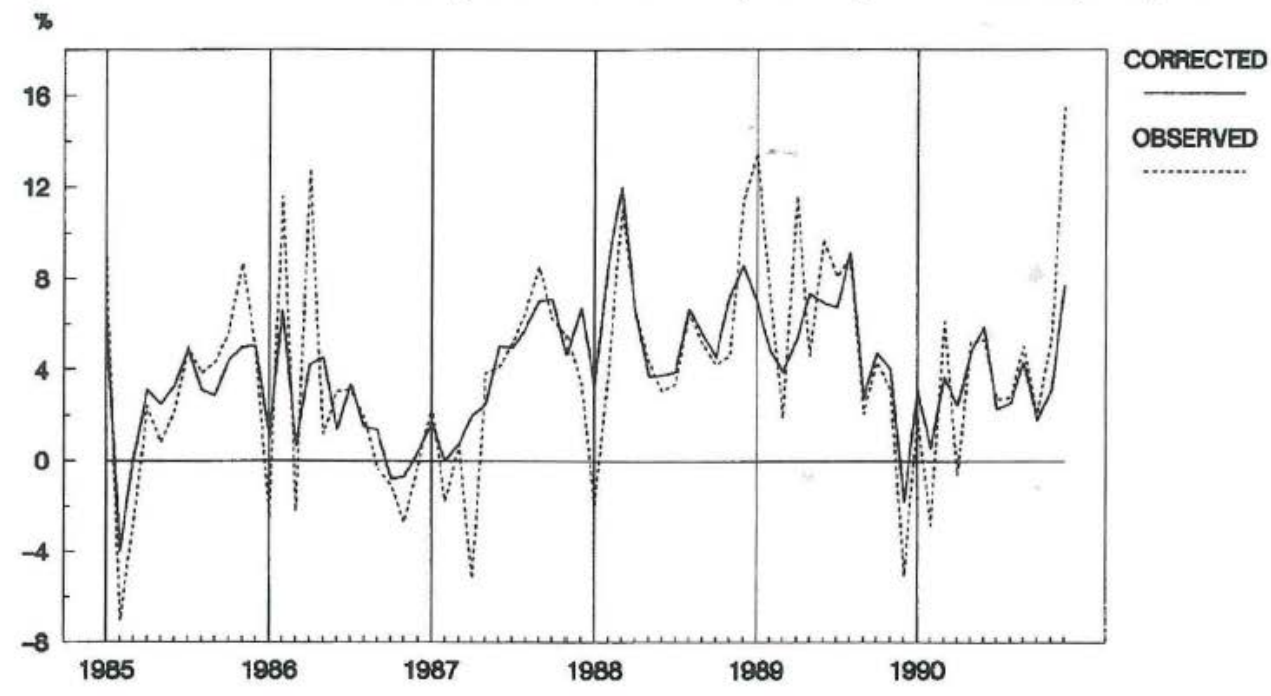

NOTE: Growth is computed as relative change with respect to the same month of the previous year 


\section{Conclusions}

In this paper we have tried to show the potential contribution of time series models to the analysis of high frequency data of economic activity. Although most people consider them just a forecasting tool, we have drawn attention to their central role in the acquisition, sharing, and use of knowledge within an organization. This view concurs with recent developments in management science, which favour organizational memory and a publicly documented body of knowledge, as opposed to personal knowledge that is lost when a long-time employee leaves the organization [7].

We have argued that forecasting is not the only application of TSM. There are other by-products which may become as important as direct extrapolation from the observed historical record. Simulations and signal extraction provide valuable information for the planning process. The former goes one step further in analysing the environment, as new scenarios can be defined and their influence quantified; the latter, because high frequency (daily, weekly), free-from-noise signals may be aggregated into lower frequency signals (monthly, quarterly, yearly), providing managers with a much better perception of the underlying trends in the observed data.

\section{Acknowledgements}

This paper is based upon work supported by the Spanish DGICYT, projects PB93-0236 (both authors) and PB93-0653 (Cancelo).

\section{References}

1 Murdick, R.C. and Georgoff, D.M. (1993) 'Forecasting: a systems approach', Technological Forecasting and Social Change, Vol. 44, pp.1-16.

2 Hogarth, R.M. and Makridakis, S. (1981) 'Forecasting and planning: an evaluation', Management Science, Vol. 27, pp.115-138.

3 Goodwin, P. and Wright, G. (1994) 'Heuristics, biases and improvement strategies in judgmental time series forecasting', Omega, Vol. 22, pp.553-568.

4 Brown, L.D. (1988) 'Editorial: comparing judgmental to extrapolative forecasts: it's time to ask why and when', International Journal of Forecasting, Vol. 4, pp.171-173.

5 Goodwin, P. and Wright, G. (1993) 'Improving judgmental series forecasting: a review of the guidance provided by research', International Journal of Forecasting, Vol. 9, pp.147-161.

6 Ashouri, F. (1993) 'An expert system for predicting gas demand: a case study', Omega, Vol. 21, pp.307-317.

7 Schultz, R.L. (1992) 'Fundamental aspects of forecasting in organizations', International Journal of Forecasting, Vol. 7, pp.409-411.

8 Nevis, E.C., DiBella, A.J. and Gould, J.M. (1995) 'Understanding organizations as learning systems', Sloan Management Review, Vol. 36, pp.73-85.

9 Makridakis, S., Wheelwright, S.C. and McGee, V.E. (1983) Forecasting: Methods and Applications, John Wiley \& Sons, New York.

10 Remus, W.E. (1991) 'Criterion-referenced judgmental forecasting models', Journal of Forecasting, Vol. 10, pp.415-423. 
11 Bogard, C., George, G., Jenkins, G.M. and McLeod, G. (1982) 'Analysing a large number of energy time series for a utility company', Chapter 5 in G.M. Jenkins and G. McLeod (eds., 1982) Case Studies in Time Series Analysis, Gwilim Jenkins \& Partners Ltd., Lancaster.

12 Bunn, D.W. and Farmer, E.D. (eds., 1985) Comparative Models for Electrical Load Forecasting, John Wiley \& Sons, New York.

13 Gross, G., and Galiana, F.D. (1987) 'Short-term load forecasting', Proceedings of the IEEE, Vol. 75, pp.1558-1573.

14 Adams, G., Allen, P.G. and Morzuch, B.J. (1991) 'Probability distributions of short-term electricity peak load forecasts', International Journal of Forecasting, Vol. 7, pp.283-297.

15 Engle, R.F., Mustafa, C. and Rice, J. (1992) 'Modelling peak electricity demand', Journal of Forecasting, Vol. 11, pp.241-251.

16 Cancelo, J.R. and Espasa, A. (1996) 'Modelling and forecasting daily series of electricity demand', Investigaciones Económicas, XX(3), pp.359-376.

17 Box, G.E.P., Pierce, D.A. and Newbold, P. (1987) 'Estimating trend and growth rates in seasonal time series', Journal of the American Statistical Association, Vol. 82, pp.276-282.

18 Mills, T.C. (1990) Time Series Techniques for Economists, Cambridge University Press, Cambridge.

19 Cleveland, W.P. and Grupe, M.R. (1982) 'Modelling time series when calendar effects are present (with discussion)', in A. Zellner (ed., 1982), Applied Time Series Analysis of Economic Data, Bureau of the Census, Washington.

20 Bodo, G., Cividini, A. and Signorini, L.F. (1991) 'Forecasting the Italian industrial production index in real time', Journal of Forecasting, Vol. 10, pp.285-299.

21 Cancelo, J.R. and Espasa, A. (1991) 'New weekly and monthly indicators of activity based on electricity consumption' (in Spanish), Documento de Trabajo 9106, Economics Department, University Carlos III of Madrid. 